\title{
The role of communication and collaboration in English language teaching during uncertain times - report
}

\author{
ISSN 2657-9774; https://doi.org/10.36534/erlj.2021.01.07
}

Luisito M. Nanquil

Graduate School, Bulacan State University, the Philippines; luisito.nanquil@bulsu.edu.ph

\begin{abstract}
Language teaching in the new normal requires patience, creativity, flexibility, and reflection. Both teachers and students are having onerous and laborious situation in coping with all the predicaments and challenges brought about by the disruptive pandemic. This reflective-narrative paper narrates and describes how the author, being a seasoned language teacher, has been coping with the trials and complexities of the new normal. At the end of the anecdotal narration and report, new insights and tips are offered to readers and language teachers who are at the same boat. All struggles of learners and teachers have products and outcomes which are in the form of lessons and experiences making them better individuals despite the ever-changing and challenging dimensions of distance education and home learning.
\end{abstract}

Key words: language teaching, communication, collaboration, flexible instruction, pandemic

\section{Language teaching in the new normal}

The situation since last year until now is laborious and stressful. Both language teachers and their students find it difficult to meet using online platform due to some issues like equipment, materials, and connectivity. Communication is filled with complexity and challenge on today's teaching-learning situation. I would like to narrate my professional and personal experiences on language teaching during pandemic time.

The adjustment to handle courses in a new learning environment demands a lot of time. I did not only consider the digital skills but also the connectivity I am using in my class and the situation in which my students are into. Even if the teacher has all the skills and resources to teach the subject, if the students do not have means and resources then things are pointless.

In my school, we have tried modular distance learning and online distance instruction as choices of our students to engage in the process of learning. On its first implementation, we have had layers of glitches and flaws on the process but as time went on it became smooth although until now few challenges are still seen.

This paper aims to present, share, and narrate the personal and professional experiences of the author-researcher by identifying turning points during the time of pandemic. He describes how communication and collaboration played important role in making online teaching and learning inclusive and accessible to all students.

From my own encounter, collaboration and communication were very helpful in sustaining and protecting the social and emotional aspects of students. In developing the macro-skills, vocabulary, and critical thinking skills of students, collaboration and communication have useful and functional roles.

I am always trying to understand the different reasons and stories that my students tell in the class. Others cannot make it in the class due to difficulty in connectivity or insufficient funds to purchase data. As a language teacher and counselor of my own classes, I have to be flexible and reflective on their thoughts and words. I am trying to blend different approaches and strategies that will allow all learners to get access to my lessons and modules in a meaningful way.

I have this segment called "online forum" in which learners get the chance to express their ideas and share their thoughts regrading a particular lesson and experience they have had in the virtual sessions. They can also type their own stories of success and realization during the time of calamity 
and pandemic just like what they are experiencing now. From this activity, they can communicate with their classmates, who are members of the community forum. All members can react and comment but of course decorum is strictly implemented. They can also collaborate on the activities, tasks, and projects.

\section{Challenges}

Having taken this opportunity to raise some issues on distance learning and language teaching, I would like to present some thoughts of my students regarding the current situation and their reactions. Not only the students are hugely devastated by the impact of pandemic but also their parents. Many companies and schools ceased operations due to decreased profit among others. Some parents do not even know how to start all over again.

\section{Literature review}

Marzano and Toth (2014) explain that the traditional teacher-centered pedagogy/approach has limitations. Rather than increasing student outcomes and independence, students may be spending the core of their time just listening. If learners spend most of their time at lower levels of thinking, students may find themselves unready for more challenging assessment tasks.

The significance of linking the part to the whole is a main point from Bailey and Pransky (2014) as they provide guidance in helping students collect information to long term memory. They say that when students are doubtful about the main idea or goal of what they are studying, their brains tend to either frantically search for meaning and connections, which covers precious active memory space, or zone out and give up on knowing what is happening. Simply state, seeing how the parts fit into the big piece helps learning more feasible.

Creating learning experiences that balance teacher explanation and student discovery requires reflection on what a lesson should contain and perhaps even the tasks of the teacher. The professional reward depends on the outcomes of seeing how students successfully carry out tasks and providing feedback to share in their learning and what caught their interests.

Malcolm Gladwell in David and Goliath (2013) also shares about a special capacity some people possess for overcoming tremendous adversity in order to achieve victory. A gleaming example of his finding includes a number of students who became successful in their chosen career despite issues on dyslexia and other learning disabilities.

Even students graduating from prestigious business schools with MBAs are often lacking the skills employers are seeking for. This was a picture from the message of Bloomberg (Levy \& Rodkin 2015). About 614 employers responded to a survey that asked not just about the traits they required from candidates but also their attributes that are most difficult to find. Their results were showcased in a dynamic online graphic called "the skills gap". Moreover, the survey indicated that these skills which employers most desire among candidates but have most difficulty finding: creative problem-solving, strategic thinking, leadership, and communication skills.

An advance organizer which is a linkage to previous knowledge can provide a way to students for them to acquire information more effectively and demonstrate to students an image of success (Hattie and Yates 2014).

Learner engagement, autonomy, pedagogical tasks, increased opportunities to spend time with students learning through multiple perspectives are good start for a favorable list.

Stations are not only bridge to incorporate movement during sessions. Students can stand to exchange notes, work problems, or play a vocabulary enrichment game. At the very minimum, learners can take a swift stretch break during lesson breaks. Learning stations, by their nature and purpose, can infuse purposeful student movement. Also called centers, learning stations may have an elementary image, but they are an integral instructional device and technique for all ages.

Movitz and Holmes (2007) share their experiences in teaching high school where they incorporated learning stations while handling a medieval unit. One key point on their reflection is that learners don't outgrow their love of learning through hands-on and multisensory tasks. They witnessed increased student participation and more meaningful experiences through stations. 
Cooperative learning, on the other hand, can be an effective mixture together and simply asking students to work together lacks the organization and same goals of effective cooperative learning. Cooperative learning is not just working in groups; rather, it is purposive, tactical, and structured instructional strategy that can promote healthy learning environment.

Fielder and Brent (2007) provide logical reasons as to why cooperative learning is attainable and effective. Students can learn better by performing something active, rather than simply sitting and listening. They also believe that cooperative learning benefits smarter students, who are put in the position of having to explain and summarize concepts to team members who contribute to success of the team.

Macmillan (2021) online course offers insight that says building relationships that are meaningful and not just transactional. The teacher has to allocate time in each lesson to learn about the lives of his students. The teacher should find out what inspires students and what they feel passionate about. They can also talk about themselves and value communication practice. With the chance provided by the teacher to understand his students and understand one another, this situation forges stronger bonds among members of the class leading to creating a more supportive and inclusive classroom environment.

It also suggests teachers to be transparent by offering full disclosure on why the teacher presents the lesson and how tasks and materials are designed to help students achieve progress. Explaining the purpose of the tasks, activities, and approaches to students provide them a roadmap for completion and motivation.

\section{Challenges and issues on language teaching during pandemic}

Having taken this opportunity to raise some issues on distance learning and language teaching, I would like to present some thoughts of my students regarding the current situation and their reactions. Not only the students are hugely devastated by the impact of pandemic but also their parents. Many companies and schools ceased operations due to decreased profit among others. Some parents do not even know how to start all over again.

Teaching in the time of pandemic has never been easy due to disruptions in connectivity and livelihood of people. A number of students are trying their best to attend online and modular classes because they do not want to be left in learning and interaction. It is the belief of many Filipino students that knowledge and ideas they can get from school will be their weapon for future battle.

As such, I being a language teacher try to provide flexible instruction that can reach learners despite distance and situation we are currently experiencing. I am using communication and collaboration to achieve my objectives for each module being tackled in my online and modular classes. It is pivotal that I am posting reminders and announcements using the google classroom and Facebook as my channels to communicate all thoughts and ideas. Students get the chance to interact and ask their questions while they are included or enrolled on the platform we are using. In addition, I am grouping the students with seven members each. They are allowed to brainstorm, interact, and consult one another. I am employing project-based learning, differentiated instruction, and taskbased instruction while all of them are embarked on virtual instruction.

I am making sure that each session, my students are in good shape. This is why I am asking them "how are you" and "how is your day"? This is one way how I can feel their condition and reflection. If they have concerns, I provided a button and platform where they can communicate with me for consultation and guidance.

Despite global disruption of the pandemic, I believe quality education has to go on and continue. In varied ways, flexible teachers can do many things to ensure holistic development of learners. The power of communication and collaboration can help both teachers and students to do their best and unleash their potentials despite threat of the situation. I have this perspective that language teachers need to get more webinar-training session on online teaching and assessment because even after the uncertain time like this, flexible instruction and distance education will never be removed anymore. If all resources and approaches are available, then this kind of modality and instruction has to continue because it allows people from different parts of the globe to collaborate and communicate. learning 
together and professional community learning have paved way to gigantic ideas, concepts, and opportunities making students become dynamic and reflective.

\section{Conclusion and insights}

This reflective-narrative paper aims to describe and share the experiences of the author as regards language teaching with the use of communication and collaboration. Teaching the macroskills and vocabulary in the online ESL class may not be easy due to different challenges both teachers and students encounter. From the experiences and observations of the author, it can be said that communication and collaboration as $21^{\text {st }}$ century skills are more than necessary to prepare learners on the present and future challenges of the worksite or workplace by giving them the opportunities to express, interact, share, and collaborate for the success of any lesson or project in the class.

Teachers can support the development of learning skills of students while they allow them with space to respond and evaluate what tasks and activities work best for them. Students can also carry out reflection tasks at the end of each lesson. Teachers can create tick-box evaluation forms to help learners identify what they discovered most engaging and which tasks helped them learn most effectively. Using varied strategies, teachers can offer students alternative routes through the learning jungle that will increase their chances of reaching their temples at the same time, allowing them pick up gold along the way.

In a positive learning environment, learners are engaged, safe, connected, and supported. Healthy and safety issues and efficient communication with both parents and teachers are also highly emphasized for a successful learning outcome. In this aspect, the role of collaboration plays a significant role. By incorporating collaborative and learner-centered strategies, teachers can make a difference in the lives of students hence, preparing them for the real world and the workplace.

\section{References}

Bailey, F., \& Pransky, K. (2014). Memory at work in the classroom: Strategies to help underachieving students. Alexandria, VA: ASCD.

Fielder, R. M., \& Brent, R. (2007). Cooperative learning. In P.A. Mabrouk (Ed.), Active learning: Modules from the analytical sciences. Washington, D.C. American Chemical Society, 34-53.

Hattie, J. (2012). Visible learning for teachers: Maximizing impact on learning. New York: Routledge. Hattie, J., \& Yates, G. (2014). Visible learning and the science of how we learn. New York: Routledge. Levy, F., \& Rodkin, J. (2015). The Bloomberg recruiter report: Job Skills companies want but can't get. Bloomberg. Retrieved from http://www.bloomberg/graphics/2015-job-skills-report/.

Marzano, R.J., \& Toth, M.D. (2014). Teaching for rigor: A call for a critical instructional shift. Learning Sciences Center Monograph. York, PA: Learning Sciences International.

Movitz, A.P., \& Holmes, K.P. (2007). Finding center: How learning centers evolved in a secondary, student-centered classroom. English Journal, 96(3), 68-73.

(2021). www.macmillanenglish.com 